\title{
Potential genetic benefits of mate selection in whitefish
}

\author{
C. WEDEKIND, ${ }^{*}+\ddagger$ R. MÜLLER* \& H. SPICHER \\ *Swiss Federal Institute for Environmental Science and Technology (EAWAG), Department of Fisheries Science, Kastanienbaum, Switzerland \\ †Department of Biology, University of Utah, Salt Lake City, UT, USA \\ $\$$ Institute of Cell, Animal and Population Biology, University of Edinburgh, Edinburgh, UK \\ \$Labor Weissenbühl, Chutzenstr., Bern, Switzerland
}

Keywords:

breeding tubercles;

conservation;

Coregonus;

genetic heterogeneity;

good genes hypotheses;

fish hatchery;

parasite-driven sexual selection;

parasite resistance;

Pseudomonas fluorescens;

supportive breeding.

\begin{abstract}
To test the potential of optimal mate selection with respect to offspring viability, we crossed 10 female and 10 male whitefish in all possible combinations and reared the resulting 100 sib groups in several replicates. We recorded two types of egg mortality, one that was correlated to developmental problems, and a later one that was correlated to a bacterial infection. We found strong maternal and paternal effects in both types of mortality. Early mortality also depended on which female was mated with which male, suggesting partial incompatibilities. The later mortality, but not the former, could be predicted by male breeding ornamentation. More strongly ornamented males sired offspring that better survived the epidemic during egg development. This 'good genes' effect was larger than expected from theory: optimal mate selection would have improved offspring survival during the epidemic by about $12 \%$ (or reduce mortality by about $66 \%$ ) as compared with random mating.
\end{abstract}

\section{Introduction}

Every year, millions of whitefish, salmon, and other fish are caught during the breeding season and stripped for artificial breeding. After some rearing efforts, progeny are normally released to support the natural populations. These progeny stem from parents that did not choose each other, although in nature, mating is usually not random. There are other breeding programmes (e.g. in zoos) that appear to neglect the potential benefits of natural mate preference, although a number of evolutionary models predict that free mate choice enhances the survival chances of the offspring.

Much evidence has been collected for nonrandom mating, especially for female mate preferences, in a variety of taxa (Andersson, 1994). The existence of female mating preferences is seldom questioned when considering species in which males differ in their relative ability to provide resources or care for the offspring.

Correspondence: Claus Wedekind, Institute of Cell, Animal and Population Biology, University of Edinburgh, West Mains Road, Edinburgh EH9 3JT, UK.

Tel.: 13165054 54; fax: 13165065 64;

e-mail: c.wedekind@ed.ac.uk
However, when males provide neither resources nor parental care, the maintenance of female mating preferences is less clear and has been a matter of debate. There are now two major classes of models that could explain mate preferences in these cases. One class of models derived from Fisher (1930) proposes that mate choice can be based on traits that are attractive to members of the opposite sex and do not reveal anything apart from that (Lande, 1981; Kirkpatrick, 1982; Pomiankowski et al., 1991; Pomiankowski \& Iwasa, 1998). The other class of models, the so-called 'good genes hypotheses', predict that mate choice enhances the survival chances of the offspring by selecting beneficial genes (reviewed in Kirkpatrick \& Ryan, 1991; Andersson, 1994; Wedekind, 1994a; Westneat \& Birkhead, 1998). These models often assume that coevolution with parasites is the driving force, because constantly changing selection by parasites may prevent sexual selection from depleting variation in heritable fitness (Hamilton \& Zuk, 1982; Eshel \& Hamilton, 1984).

The general view on the heritability of fitness is that it typically falls between 1 and 10\% (Burt, 1995; Kruuk et al., 2000), and that the fitness benefit from mate selection for good genes is weak (Kirkpatrick $\&$ Barton, 
1997). A recent meta-analysis on the available data on 'good genes' effects in sexual selection (Møller \& Alatalo, 1999) suggests that male characters chosen by females reveal on average only $1.5 \%$ of the genetic component of variance in offspring viability. However, this metaanalysis also revealed considerable heterogeneity in effect sizes among the studies, with a bias towards few vertebrate taxa (Møller \& Alatalo, 1999). Moreover, in most species that have been studied, female choice for good genes could, in principle, be confounded by nongenetic benefits, e.g. the amount of care a male is able or willing to provide (e.g. Milinski \& Bakker, 1990; Hill, 1991; Iyengar \& Eisner, 1999), differences in the number of eggs or egg quality that could be conditionally biased by the female in response to the attractiveness of her mate (Norris, 1993; Petrie \& Williams, 1993; Petrie, 1994; Hasselquist et al., 1996; Wedekind et al., 1998; Gil et al., 1999; Newcomer et al., 1999; Cunningham \& Russell 2000, 2001), or male intra-sexual interactions (Partridge, 1980; Crocker \& Day, 1987; Taylor et al., 1987; Promislow et al., 1999). A study that experimentally eliminated all these potential confounding factors (Welch et al., 1998) provided strong evidence that offspring viability can have a genetic basis. However, whether this variation in offspring viability was connected to different parasite susceptibilities, as often proposed by the 'good genes models', remained unclear.

Alpine whitefish (Coregonus sp., the taxonomy of these coregonids has not yet been solved, see Douglas et al., 1999) are typically caught during the breeding season, their gametes stripped into large beakers for artificial breeding, and the eggs and larvae are reared for some time before they are released into the wild. This procedure neglects any potential benefits of mate choice, despite the fact that most if not all fish studied do not randomly mate but have sophisticated mating systems (Taborsky, 1994). Whitefish are group-spawning fish and develop a breeding ornamentation shortly before the mating season. This ornamentation is typical for many teleost species and consists of breeding tubercles (Wiley $\&$ Collette, 1970). These are little horn-like and colourless structures which, in the case of whitefish, are distributed laterally over the skin. They grow before the breeding season and fall off shortly afterwards.

The mating system of whitefish is not well known. We suspect that it may be similar to the one in roach (Rutilus rutilus), another group-spawning fish of similar size that also develops breeding tubercles shortly before mating. Roach have a lek-like mating system with different male reproductive strategies, and with females differing in their spawning preferences (Wedekind, 1996).

Female whitefish produce many thousand eggs per breeding season which are externally fertilized. There is no parental care after fertilization and no mate guarding before. This biological background, and the fact that there are well established standard procedures for stripping and rearing whitefish eggs (Rösch, 1995), enabled us to directly study the potential genetic effects of mate selection without having to control for the potential confounding variables indicated above. Here we used wild caught whitefish to test (i) whether males differ in their genetic quality as measured in the viability of their offspring, (ii) whether these differences could be predicted by the males' breeding ornamentation, and (iii) whether there are significant interactions between maternal and paternal effects that influence the survival of the offspring.

\section{Materials and methods}

Ten male and 10 female whitefish were randomly picked out of a large number of fish that had been caught during the breeding season using a gill net in Lake Hallwil in Switzerland. The gametes of the fish were stripped individually into Petri dishes. These gametes were used to produce all possible parental combinations, i.e. $100 \mathrm{sib}$ groups. Therefore, the eggs from each female were approximately evenly distributed in 10 new Petri dishes. A $10 \mu \mathrm{L}$ of milt was added with a micropipette into each Petri dish. Then, the Petri dish was half filled with lake water and shaken gently for about $5 \mathrm{~s}$. The freshly fertilized eggs were then transported to the laboratory. Here, the water was changed and the eggs from each Petri dish were distributed in four new Petri dishes (diameter $=9 \mathrm{~cm}$, water level $=$ about $1 \mathrm{~cm}$, no cover $)$ on the same day. The mean number of eggs per Petri dish was $139.8(\mathrm{SE}=2.6)$. Care was taken to randomize the position of these 400 Petri dishes in the climate chamber (randomized block design with respect to parental origin and to shelf in the climate chamber). During regular checks (at least three times per week), dead, misdeveloped and obviously infected eggs were removed with a pipette and their quantity marked at the border of each Petri dish. As we expected the eggs to take about 60 days to hatch at $8{ }^{\circ} \mathrm{C}$ (Ventling-Schwank \& Müller, 1991), we decided a priori to record the cumulative mortality until the 30th day as the 'early mortalilty' (including all possibly nonfertilized eggs), and the remaining mortality until hatching as 'late mortality' (number of dead eggs between day 30 and hatching/number of live eggs at day 30). Water was exchanged every 2 weeks during the first 30 days, and once per week from then on, by emptying the Petri dish over a stiff piece of nylon net $(1000 \mu \mathrm{m})$ and immediately adding sand filtered lake water that had been stored for at least 1 day in an aerated aquarium in the climate chamber. No effort was taken to keep the water exchange procedure aseptic, and infections were not treated.

Regular checks under a microscope indicated that the early mortality was mainly because of developmental abnormalities of the embryos. Mortality appeared to decrease until day 30. Shortly after the third water exchange, i.e. between the 35th and the 40th day, a marked increase in mortality was observed that was 
phenotypically new and clearly distinct from the early mortality. This new mortality appeared to be caused by an infection, as indicated by the clustered occurrence of dead eggs and the point-like and rapid spread of the disease within the Petri dishes (in another sample of whitefish eggs that were simultaneously incubated in the room, we documented the spreading of the disease in eight Petri dishes by photographs and observed an increase in prevalence from an average of $5 \%$ to an average of $23 \%$ within 3 days). Accordingly, all the eggs analysed for bacterial infection contained Pseudomonas fluorescens, a virulent bacterial fish disease (Schäperclaus et al., 1990).

The breeding ornamentation of whitefish is typical for many teleost species and consists of breeding tubercles (Wiley \& Collette, 1970). To preserve the size and measure of the breeding tubercles, we made plaster casts of the right body side of each male the day they were stripped (Wedekind, 1992). In order to get a measure of the breeding ornamentation (i.e. a potential measure of male quality), the average cast depth from the largest 10 tubercles near the side line vertically above the anal fin were measured with a Digimatic Indicator 0.001-50 mm (Mitutoyo Kanagawa, Japan). This procedure was chosen a priori because the skin of the fish was often damaged at other places during catching in the gill nets. As fish length and average tubercle size were not significantly correlated $(r=-0.006, n=10, P=0.99)$, these average tubercle sizes were not corrected for body size. Scales from above the lateral line below the dorsal fin were used to age the fish.

The Petri dishes were the units of analysis in the statistics on egg mortality. When testing for a correlation between breeding tubercles and offspring mortality, the 400 batches of offspring ( 40 per male) were analysed in a directed Anova. This procedure tests for between-male differences while taking an a priori expectancy into account, i.e. it combines an one-way Anova with the Spearman rank order correlation coefficient between observation and expectancy. Here, it includes the a priori expectancy that offspring mortality decreases with increasing male tubercle size. Another feature of the test is that it avoids the typical problem of one-tailed testing, i.e. the inflation of the $\alpha$-value. See a more detailed description of the procedure in Rice $\&$ Gaines (1994a, b).

\section{Results}

Early and late mortality were not significantly correlated (see Fig. 1 for a direct comparison of the mortalities; test within fathers: Pearson's $r=-0.29, n=10, P=0.42$; within mothers: $r=0.13, n=10, P=0.72$ ). Therefore, early and late mortality are two different measures of progeny quality. There were clear maternal and paternal effects in both types of mortality (Table 1). Early mortality was also dependent on which female was mated with which male, but no such interaction was observed

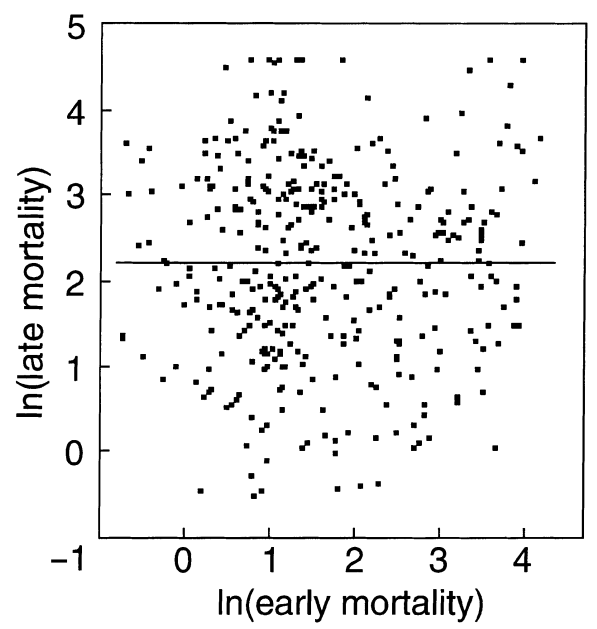

Fig. 1 Early mortality, which is correlated to developmental problems, compared with late mortality, which is correlated to bacterial infection. The figure shows the ln-transformed data (to improve graphical description) and the regression line. See text for statistics.

Table 1 Two-way Anova (random model) of parental effects on the offsprings' early and late mortality.

\begin{tabular}{lrrrc}
\hline Source of variation & SS & d.f. & \multicolumn{1}{l}{$P$} \\
\hline Early mortality & & & & \\
$\quad$ Mother & 4.91 & 9 & 104.39 & $<0.0001$ \\
$\quad$ Father & 0.10 & 9 & 2.14 & 0.035 \\
$\quad$ Mother $\times$ Father & 0.42 & 81 & 2.52 & $<0.0001$ \\
$\quad$ Error & 0.62 & 300 & & \\
Late mortality & & & & \\
$\quad$ Mother & 1.21 & 9 & 4.69 & $<0.0001$ \\
$\quad$ Father & 0.85 & 9 & 3.28 & 0.002 \\
$\quad$ Mother $\times$ Father & 2.32 & 81 & 0.85 & 0.81 \\
$\quad$ Error & 10.17 & 300 & & \\
\hline
\end{tabular}

with respect to late mortality (interaction terms in Table 1).

The information about offspring mortality allowed us to determine which pair of parents would be optimal with respect to offspring viability. When the optimal male of all 10 males were chosen for each female, the most successful pairings with respect to early mortality resulted in a $3.5 \%$ average increase of offspring survival, or an average mortality decrease by up to $32.6 \%$, as compared with random mating (Fig. 2a). The males' breeding ornamentation did not significantly predict this offspring mortality (directed ANOVA, $F_{9,390}=0.73$, $\left.\mathrm{r}_{\mathrm{S}} P_{C}=0.04, P>>0.05\right)$. The amount of variance in early offspring mortality predicted from our measure of breeding ornamentation is $r^{2}=0.04$ (Pearson's $r$ ).

Analogously, the most successful pairings with respect to late mortality resulted on average in $11.9 \%$ increased offspring survival, and decreased mortality by up to $66.4 \%$, as compared with random mating (Fig. 2b). The 


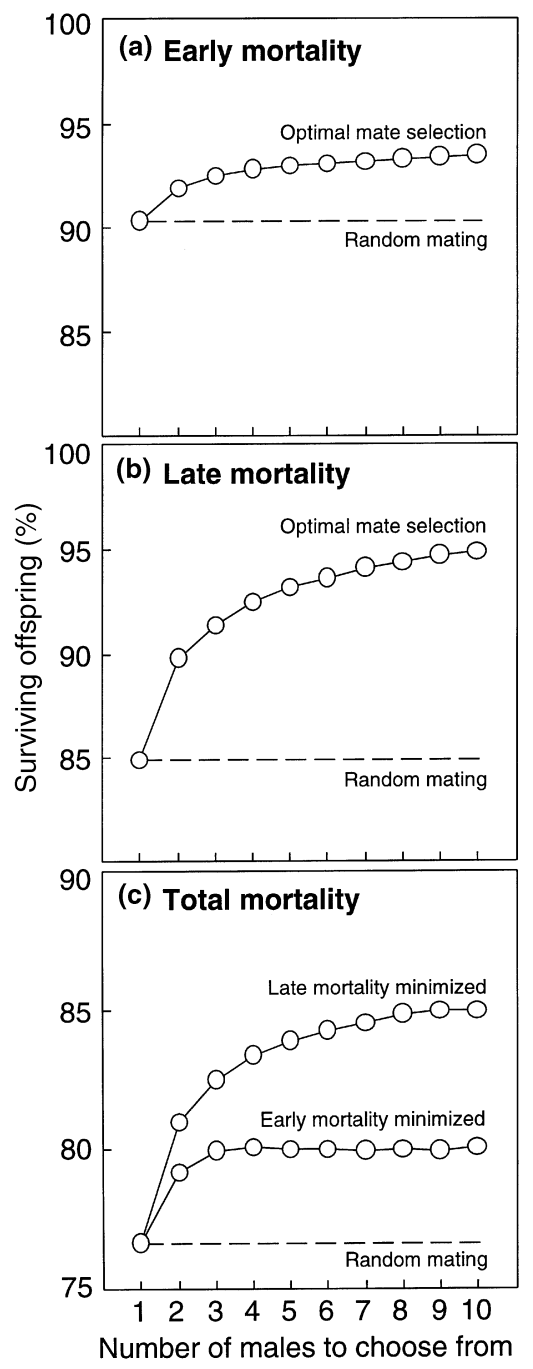

Fig. 2 Mean percentage of surviving offspring with respect to (a) early mortality, and (b) late mortality when the optimal male (with respect to offspring mortality) would be selected for each female out of a given number of males ( $x$-axis). The circles give the means of 1000 random assignments each. The hatched line gives the observed mean survival rates of all possible pairings, i.e. the mean outcome of complete random mating. (c) Total survival that would result if mate selection could minimize for late or for early mortality of the offspring, again plotted against the number of males one could choose from to indicate the effect of sampling.

breeding ornamentation was significantly predictive of this late offspring mortality (Fig. 3). The amount of variance in late offspring mortality predicted from our measure of breeding ornamentation is $r^{2}=0.32$ (Pearson's $r$ ).

Because early and late mortality were not significantly correlated, optimizing mate choice for both types of mortality would be difficult. However, $65 \%$ of the total egg mortality was the result of the late mortality. If mate selection were optimized for late mortality, total survival

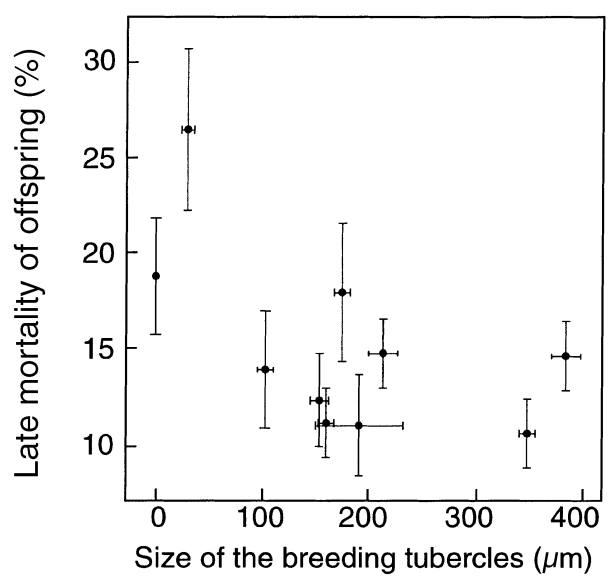

Fig. 3 Size of the breeding tubercles of the fathers compared with late mortality of their offspring. Late mortality was determined in 40 batches of offspring per male, and 10 tubercles per male were measured. The figure shows mean \pm SE. Late offspring mortality decreases with increasing size of breeding tubercles [directed ANOvA (Rice \& Gaines, 1994a, b), $\left.F_{9,390}=2.68, \mathrm{r}_{\mathrm{S}} P_{C}=-0.47, P=0.035\right]$.

would on average increase up to $10.9 \%$ here (when all the males were available for choice, Fig. 2c). Optimizing for early mortality would on average increase the total survival by up to $4.6 \%$ (Fig. 2c).

The males were of similar age $(2+$ and $3+$ years), but female age varied between $2+$ and $6+$ years. Female standard length and age were strongly correlated $(r=0.94, n=10, P<0.001)$, and both variables were correlated with the late mortality of the eggs: larger and older females produced eggs that suffered more from bacterial infection (correlation between late mortality and female size: $r=0.88, n=10, P<0.001$; female age: $r=0.78, P=0.008)$. Whether this was because of genetic effects (e.g. a degeneration of genetic quality during ageing), age-dependent variation in the maternal investment per egg, or simply because of cohort effect, remains unclear.

\section{Discussion}

We studied the potential benefits of optimal mate selection in whitefish, a species in which males provide nothing but sperm to the common offspring, and eggs are fertilized externally, i.e. differences of egg quality could not be biased by the female in response to the perceived quality of her mate. This makes the species an ideal model to test the 'good genes' hypotheses for sexual selection, because potentially confounding variables can be easily excluded. Moreover, as some whitefish lake populations are currently unable to recruit larvae from natural reproduction because of oxygen problems (Ventling-Schwank \& Müller, 1991), this species may be a useful model for conservation biology. Finally, whitefish are of economic importance, and any knowledge that 
can be used to improve hatcheries' efforts in supporting natural populations and hence the fisheries industry might be welcome.

The present study only addresses the potential of optimal mate selection. The approach we used allowed us to test whether there are maternal, paternal and biparental interaction effects on the offspring's survival until hatching. Moreover, measuring the males' breeding ornamentation allowed us to test whether offspring mortality could be predicted by male sexual ornamentation, a likely basis for female mate choice in nature. We had decided a priori to measure egg survival during the first and the second half of their expected development. The fact that early and late mortality were not correlated and obviously of different origin, the latter because of an infection by a well known whitefish disease that spread rapidly within affected Petri dishes, gave us the opportunity to measure two different aspects of offspring performance. The epidemic was not controlled by us and most probably spread via the nonsterile water exchange procedure. However, as we had randomized the position of the Petri dishes in the climate chamber with respect to parental origin, and hence randomized the order of the water exchange, parental effects on the late mortality caused by this random exposure to the disease can be tested in the same way as parental effects on the early mortality.

We recorded the fate of 55935 eggs of 100 different sib groups from fertilization to hatching and found significant maternal and paternal effects on both types of offspring mortality, one correlated to developmental problems and one correlated to the epidemic. The males' breeding ornamentation was a useful predictor of the latter type of mortality, but not of the former. The amount of variance $\left(r^{2}\right)$ in late offspring mortality that could be explained by our measure of male sexual ornamentation was $32 \%$. Sexual selection theory predicts that sexual ornamentation may reveal heritable fitness influenced by parasite susceptibilities rather than general viability. The effect measured here is, however, greater than theoretical predictions (Burt, 1995; Kirkpatrick \& Barton, 1997) and surpasses observations made in other empirical studies as summarized in Møller \& Alatalo (1999) (see Introduction). Our data show that the heritability of fitness as revealed by male sexual ornaments can be strong in some cases. This could have consequences for supportive breeding programmes of both endangered species and species of commercial value (Gibbons et al., 1995).

A significant interaction between maternal and paternal effects with respect to developmental problems in the offspring suggests that there are partial genetic incompatibilities between males and females, as described in other systems (e.g. Newcomer et al., 1999). The absence of a significant interaction between maternal and paternal effects with respect to the late mortality in our study suggests that males differ absolutely in their genetically based resistance against the egg disease, i.e. regardless of the maternal genetic contribution. This is different from the predictions of some models proposed before (Wedekind, 1992, 1994a, b) and suggests that breeding tubercles are honest indicators of this aspect of male quality in the sense of the handicap theory (Zahavi, 1975; Grafen, 1990).

Random outbreeding increases or maintains a high level of genetic variance in a population. Our findings, however, suggest that this variance is likely to be reduced by natural selection during egg development. Optimal mate choice would produce a somewhat lower initial genetic variance among the offspring, as variance in male reproductive success would be increased, but it could result in an increased mean survival of the offspring. Whereas random outbreeding may result in a population of hatchlings with somewhat reduced genetic variance (because of directed selection during egg development) and reduced number (because of comparatively high egg mortality), optimal mate selection already starts with a reduced genetic variance (because of high variance in male reproductive success), but more larvae may hatch. Managed breeding programmes often aim to increase or maintain a high genetic variance in a given population (Gibbons et al., 1995). Our findings question whether reducing the variance in male reproductive success, thereby increasing the initial genetic variance in a population, e.g. by random outbreeding, is a strategy that will optimally maintain a population (see also Wedekind, 2002). Random outbreeding may even support present parasite populations as this type of mating is likely to produce more susceptible offspring. This could increase the parasite pressure on other offspring and - as parasite resistance is not necessarily an all-or-nothing trait - further reduce the overall population size.

The mortality estimates in Swiss hatcheries lie within or even above the range of overall mortality calculated for random mating in our study (Ventling-Schwank $\delta$ Müller, 1991). This suggests that our laboratory situation is comparable with the hatcheries. It is not clear how well our laboratory situation reflects the wild, and it is possible that estimates of the heritability of fitness may be weaker when measured in the wild than under controlled laboratory conditions. The parasite density in our study, for example, could have become unusually high because of our enclosed system and relatively few water exchanges. However, even if parental effects are diluted in the field by uncontrolled variance (e.g. by egg predators), a carefully designed laboratory experiment would not produce an artificial parental effect. It is also possible that the field would reveal even stronger parental effects, for example if egg predators prefer eggs that are more susceptible to infection, or if stress caused by environmental changes enhances already existing differences in parasite susceptibilities.

As predicted by evolutionary models, appropriate mate selection using the males' breeding ornamentation could 
improve the offspring's survival during an epidemic, and would thereby improve the females fitness (or the hatcheries performance). The absolute fitness increase may vary from population to population depending on the kind of infection occurring at particular stages of offspring development. Our data show that the fitness increase achieved by appropriate mate selection can be much larger than previously expected.

\section{Acknowledgments}

We thank E. Fischer and A. Hofer for catching the parental fish, M. M. Bia, C. Enz, C. Rellstab, and E. Schäffer for assistance and/or discussion, and V. Braithwaite, L. Carroll, D. Penn, W. K. Potts, D. Reznick, A. M. Welch, G. C. Williams and the referees for comments on the manuscript. CW was supported by grants of the 'Berner Hochschulstiftung' and the Cloëtta Foundation, and by an IHP-grant of the Swiss National Science Foundation.

\section{References}

Andersson, M. 1994. Sexual Selection. Princeton University Press, Princeton, NJ.

Burt, A. 1995. Perspective: the evolution of fitness. Evolution 49: $1-8$.

Crocker, G. \& Day, T. 1987. An advantage to mate choice in the seaweed fly, Coelopa frigida. Behav. Ecol. Sociobiol. 20: 295-301.

Cunningham, E.J.A. \& Russell, A.F. 2000. Egg investment is influenced by male attractiveness in the mallard. Nature 404: 74-75.

Cunningham, E.J.A. \& Russell, A.F. 2001. Sex differences in avian yolk hormone levels. Nature 412: 498-499.

Douglas, M.R., Brunner, P.C. \& Bernatchez, L. 1999. Do assemblages of Coregonus (Teleostei: Salmoniformes) in the Central Alpine region of Europe represent species flocks? Mol. Ecol. 8: 589-603.

Eshel, I. \& Hamilton, W.D. 1984. Parent-offspring correlation in fitness under fluctuating selection. Proc. R. Soc. Lond. B 222: $1-14$.

Fisher, R.A. 1930. The Genetical Theory of Natural Selection. Clarendon Press, Oxford.

Gibbons, E.F. Jr, Durrant, B.S. \& Demarest, J. (eds) 1995. Conservation of Endangered Species in Captivity. State University of New York Press, Albany, NY.

Gil, D., Graves, J., Hazon, N. \& Wells, A. 1999. Male attractiveness and differential testosterone investment in zebra finch eggs. Science 286: 126-128.

Grafen, A. 1990. Biological signals as handicaps. J. Theor. Biol. 144: $517-546$.

Hamilton, W.D. \& Zuk, M. 1982. Heritable true fitness and bright birds: a role for parasites? Science 218: 384-387.

Hasselquist, D., Bensch, S. \& von Schantz, T. 1996. Correlation between male song repertoire, extra-pair fertilizations and offspring survival in the great reed warbler. Nature 381: 229-232.

Hill, G.E. 1991. Plumage coloration is a sexually selected indicator of male quality. Nature 350: 337-339.
Iyengar, V.K. \& Eisner, T. 1999. Female choice increases offspring fitness in an arctiid moth (Utetheisa ornatrix). Proc. Natl. Acad. Sci. USA 96: 15013-15016.

Kirkpatrick, M. 1982. Sexual selection and the evolution of female choice. Evolution 30: 1-12.

Kirkpatrick, M. \& Barton, N.H. 1997. The strength of indirect selection on female mating preferences. Proc. Natl. Acad. Sci. USA 94: 1282-1286.

Kirkpatrick, M. \& Ryan, M.J. 1991. The evolution of mating preferences and the paradox of the lek. Nature 350: 33-38.

Kruuk, L.E.B., Clutton-Brock, T.H., Slate, J., Pemperton, J.M., Brotherstone, S. \& Guinness, F.E. 2000. Heritability of fitness in a wild mammal population. Proc. Natl. Acad. Sci. USA 97: 698-703.

Lande, R. 1981. Models of speciation by sexual selection on polygenic traits. Proc. Natl. Acad. Sci. USA 78: 3721-3725.

Milinski, M. \& Bakker, T.C.M. 1990. Female sticklebacks use male coloration in mate choice and hence avoid parasitized males. Nature 344: 330-333.

Møller, A.P. \& Alatalo, R. 1999. Good-genes effects in sexual selection. Proc. R. Soc. Lond. B 266: 85-91.

Newcomer, S.D., Zeh, J.A. \& Zeh, D.W. 1999. Genetic benefits enhance the reproductive success of polyandrous females. Proc. Natl. Acad. Sci. USA 96: 10236-10241.

Norris, K. 1993. Heritability variation in a plumage indicator of variability in male great tits Parus major. Nature 362: 537-539.

Partridge, L. 1980. Mate choice increases a component of offspring fitness in fruit flies. Nature 283: 290-291.

Petrie, M. 1994. Improved growth and survival of offspring of peacocks with more elaborated trains. Nature 371: 598-599.

Petrie, M. \& Williams, A. 1993. Peahens lay more eggs for peacocks with larger trains. Proc. R. Soc. Lond. B 251: 127-131.

Pomiankowski, A. \& Iwasa, Y. 1998. Runaway ornament diversity caused by Fisherian sexual selection. Proc. Natl. Acad. Sci. USA 95: 5106-5111.

Pomiankowski, A., Iwasa, Y. \& Nee, S. 1991. The evolution of costly mate preferences. I. Fisher and biased mutation. Evolution 45: 1422-1430.

Promislow, D.E.L., Smith, E.A. \& Pearse, L. 1999. Adult fitness consequences of sexual selection in Drosophila melanogaster. Proc. Natl. Acad. Sci. USA 95: 10687-10692.

Rice, W.R. \& Gaines, S.D. 1994a. 'Heads I win, tail you lose': testing directional alternative hypotheses in ecological and evolutionary research. Trends Ecol. Evol. 9: 235-237.

Rice, W.R. \& Gaines, S.D. 1994b. Extending nondirectional heterogeneity tests to evaluate simply ordered alternative hypotheses. Proc. Natl. Acad. Sci. USA 91: 225-226.

Rösch, R. 1995. Rearing of coregonid (Coregonus sp.) larvae in tanks: a review. Arch. Hydrobiol. Spec. Issues Adv. Limnol. 46: 293-300.

Schäperclaus, W., Kulow, H. \& Schreckenbach, K. 1990. Fischkrankheiten (5. Auflage). Akademie-Verlag, Berlin.

Taborsky, M. 1994. Sneakers, satellites, and helpers: parasitic and cooperative behavior in fish reproduction. Adv. Study Behav. 23: 1-100.

Taylor, C.E., Pereda, A.D. \& Ferrari, J.A. 1987. On the correlation between mating success and offspring quality in Drosophila melanogaster. Am. Nat. 129: 721-729. 
Ventling-Schwank, A. \& Müller, R. 1991. Survival of coregonid (Coregonus sp.) eggs in Lake Sempach, Switzerland. Verhandl. Internatl. Verein. Limnol. 24: 2451-2454.

Wedekind, C. 1992. Detailed information about parasites revealed by sexual ornamentation. Proc. R. Soc. Lond. B 247: 169-174.

Wedekind, C. 1994a. Mate choice and maternal selection for specific parasite resistances before, during and after fertilization. Phil. Trans. R. Soc. Lond. B 346: 303-311.

Wedekind, C. 1994b. Handicaps not obligatory in sexual selection for resistance genes. J. Theor. Biol. 170: 57-62.

Wedekind, C. 1996. Lek-like spawning behaviour and different female mate preferences in roach (Rutilus rutilus). Behaviour 133: 681-695.

Wedekind, C. 2002. Sexual selection and life history decisions: implications for supportive breeding and the management of captive populations. Conserv. Biol. (in press).
Wedekind, C., Strahm, D. \& Schärer, L. 1998. Evidence for strategic egg production in a hermaphroditic cestode. Parasitology 117: 373-382.

Welch, A.M., Semlitsch, R.D. \& Gerhardt, H.C. 1998. Call duration as an indicator of genetic quality in male gray tree frogs. Science 280: 1928-1930.

Westneat, D.F. \& Birkhead, T.R. 1998. Alternative hypotheses linking the immune system and mate choice for good genes. Proc. R. Soc. Lond. B 265: 1065-1073.

Wiley, M.L. \& Collette, B.B. 1970. Breeding tubercles and contact organ in fishes: their occurrence, structure, and significance. Bull. Am. Mus. Nat. Hist. 143: 145-216.

Zahavi, A. 1975. Mate selection - a selection for a handicap. J. Theor. Biol. 53: 205-214.

Received 7 June 2001; revised 30 July 2001; accepted 18 August 2001 